Supplement of Hydrol. Earth Syst. Sci., 23, 2795-2812, 2019

https://doi.org/10.5194/hess-23-2795-2019-supplement

(C) Author(s) 2019. This work is distributed under

the Creative Commons Attribution 4.0 License.

(c) (1)

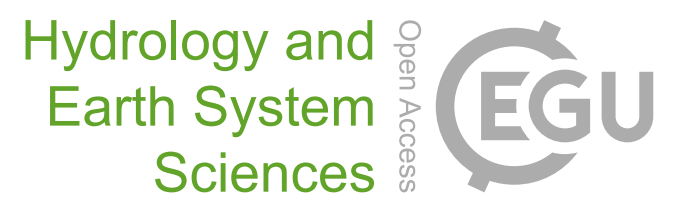

Supplement of

\title{
Influences of Lake Malawi on the spatial and diurnal variability of local precipitation
}

\section{Shunya Koseki and Priscilla A. Mooney}

Correspondence to: Shunya Koseki (shunya.koseki@gfi.uib.no)

The copyright of individual parts of the supplement might differ from the CC BY 4.0 License. 

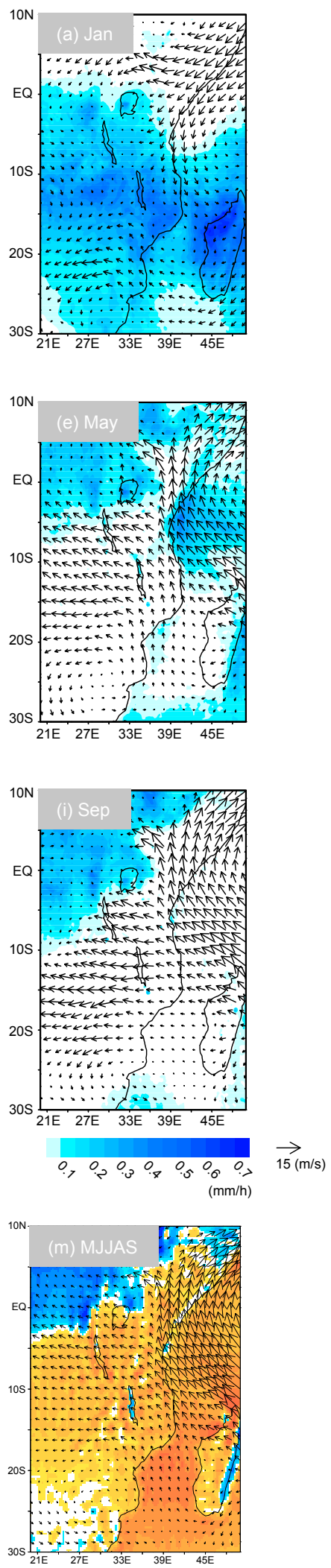

$\overrightarrow{400\left(\mathrm{kgm}^{-1} \mathrm{~s}^{-1}\right)}$
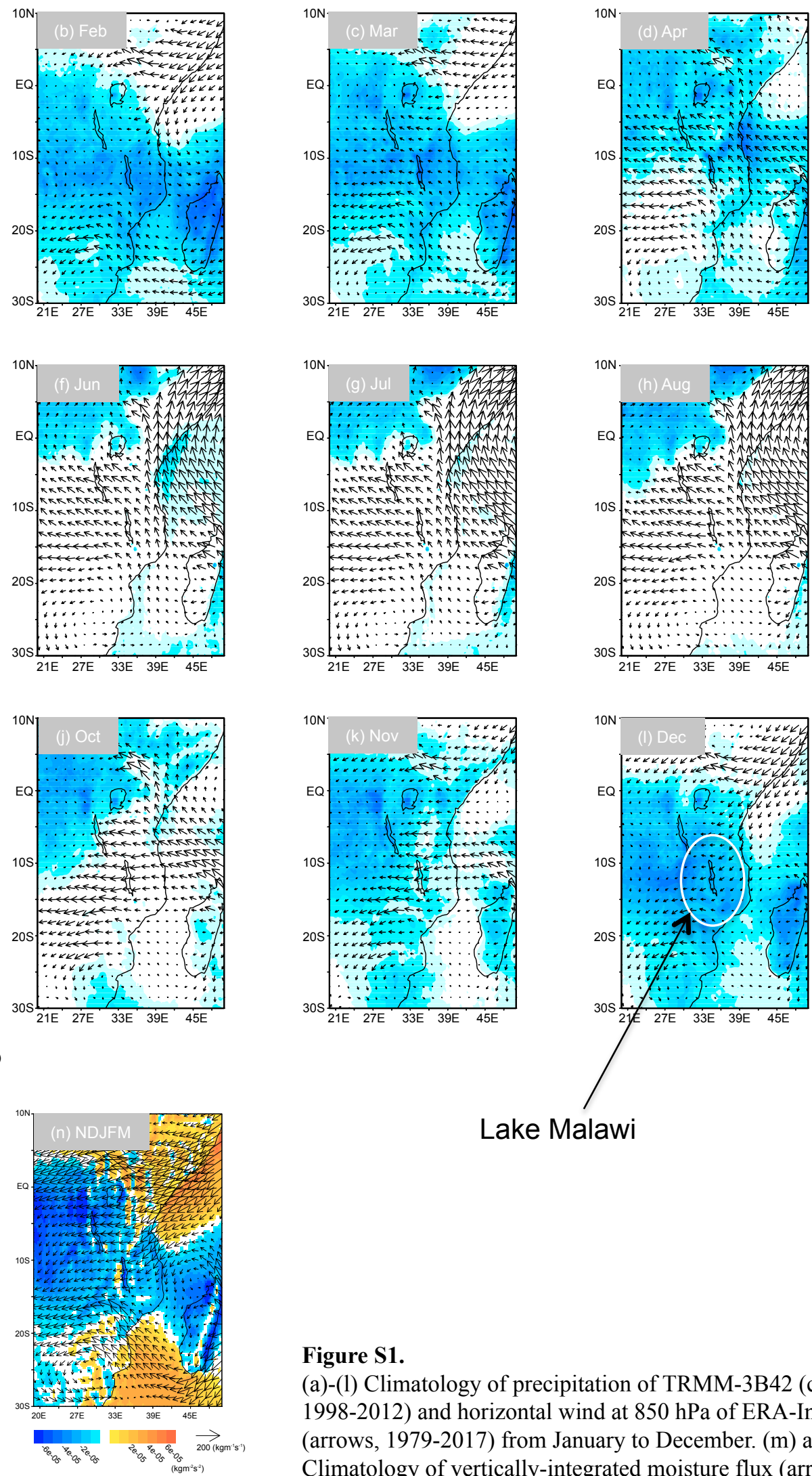
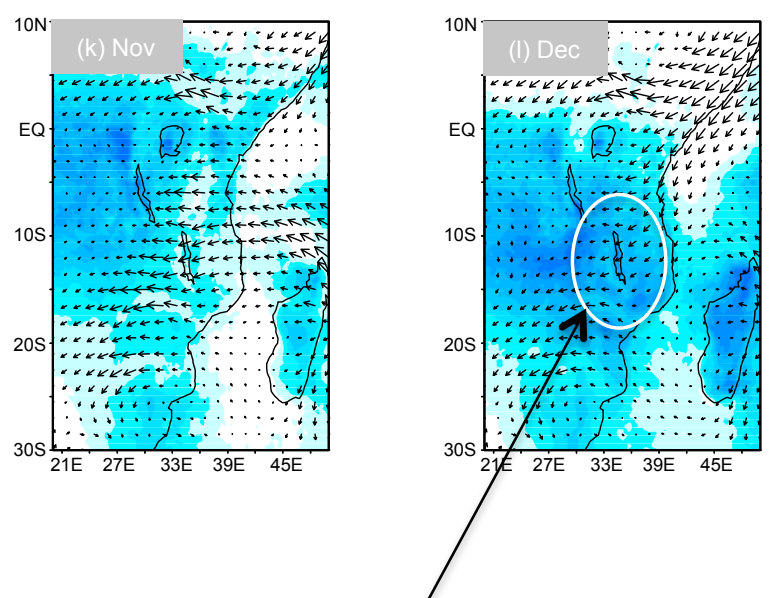

\section{Lake Malawi}

\section{Figure S1.}

(a)-(1) Climatology of precipitation of TRMM-3B42 (color, 1998-2012) and horizontal wind at $850 \mathrm{hPa}$ of ERA-Interim (arrows, 1979-2017) from January to December. (m) and (n) Climatology of vertically-integrated moisture flux (arrows) and its divergence (color) of ERA-Interim (1979-2017) for MJJAS and NDJFM mean. 